\title{
Evaluation and Optimization of Human Resource Supply in Packaging Design Project
}

\author{
Baozhong Ye ${ }^{1}$, Jian Chen*2, Jing Zhao ${ }^{3}$, Qingguang Zeng ${ }^{4}$ \\ ${ }^{1}$ School of Management, Guilin University of Aerospace Technology, Guilin, China \\ ${ }^{2}$ School of Management, Guilin University of Aerospace Technology, Guilin, China \\ ${ }^{3}$ School of Management, Guilin University of Aerospace Technology, Guilin, China \\ ${ }^{4}$ School of Management, Guilin University of Aerospace Technology, Guilin, China
}

\begin{abstract}
In order to solve the problem of selection of human resource provider for the demander in package design project, firstly, the evaluation index system of provide side is established, and the entropy weight method is used to calculate the objective weight of the evaluation index; secondly, the subjective weight is solved by the five scale valuation method, and the comprehensive weight with subjective and objective significance is obtained; then, with the help of the ideal point method, the provide side is evaluated, which can provide a reference for the choice of the demander; finally, an example is given to verify the effectiveness and practicability of the method.
\end{abstract}

\section{INTRODUCTION}

With the rapid development of packaging industry, the competition among packaging enterprises is increasingly fierce. For any packaging enterprise, the design is the key factor for its smooth operation and development [1, 2]. Zhang Haibao [3] studied the application of calligraphy elements in modern package design; Chen Xiang [4] analyzed the interesting design strategy of children's edible fungus products packaging; Ji Cheng [5] explored the current situation of the industrialization and analyzed the main development direction and specific application strategies of calligraphy in packaging design in the future. As one of the most important resources in various industries, human resource has been widely concerned because of its strong flexibility and ability to continuously learn and increase value in the process of operation. Ling Lei [6] gave the evaluation and selection method of human resource in the cloud manufacturing environment; $\mathrm{Li}$ Yanwei [7] researched the human resource management strategy of edible fungi industry; Zhang Lanxia [8] evaluated the competitiveness of technological human resource in the context of China's central cities.

The literatures above have discussed and analyzed the packaging industry and human resource and achieved important research results, however, the study of selection of human resource in packaging design project is rare. It can be said that human resource is the key factor for the success or failure of packaging design project. If packaging enterprises want to make development, they must pay attention to their packaging design, so it is inevitable that they will have to choose the human resource in packaging design project, but in most cases, it often faces multiple suppliers at the same time. Thus in this paper, the characteristics of the supply and demand sides are considered, after the establishment of the evaluation index system, the corresponding model and algorithm are used to evaluate the providers to achieve the purpose of optimization.

\section{CONSTRUCTION OF EVALUATION INDEX SYSTEM AND EXPRESSION OF PROBLEM}

\subsection{Construction of Evaluation Index System}

In the packaging design project, when the human resource demand side chooses the provide side, it needs corresponding index. Therefore, considering the characteristics of both parties and relevant factors, the following evaluation index system of the provider is established by using the QoS [9] evaluation technology.

*Corresponding author: chenjian@guat.edu.cn 


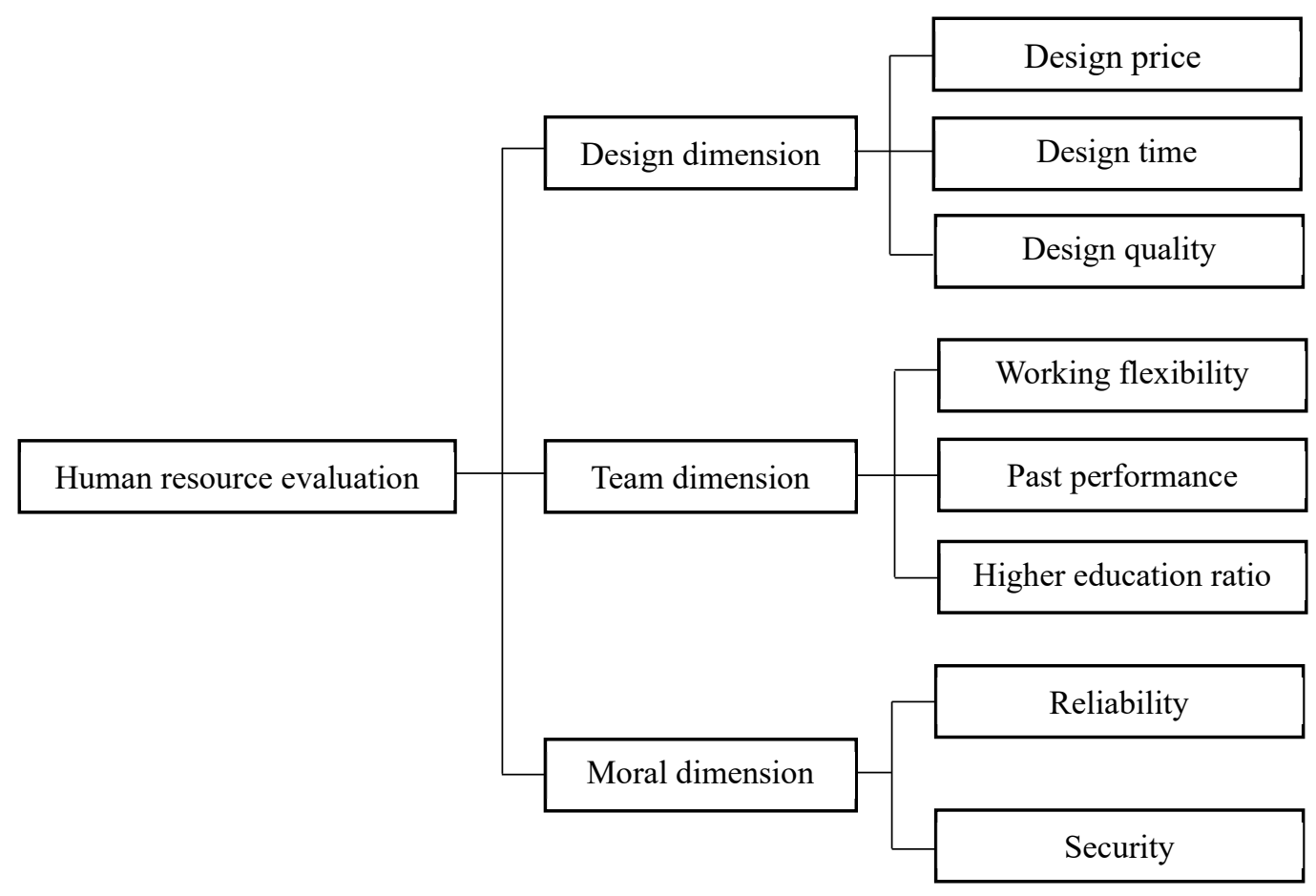

Fig 1. Evaluation index system of human resource provider in packaging design project1.

1. Design dimension: Design price $\left(p_{1}\right)$ refers to the remuneration required by the provider; design time $\left(p_{2}\right)$ means the time required of the provider to complete the project; design quality $\left(p_{3}\right)$ represents the quality of the provider to complete the project, if the times of a supplier has completed packaging design service for the corresponding demander is $\mathrm{n}$ and as the $i t h(i t h=1 \mathrm{st}$, $2 \mathrm{nd}, \ldots$, nth) time, it obtained the demander's quality evaluation is $x_{i}$, then $p_{3}=\frac{\sum_{i=1}^{n} x_{i}}{n}$.

2. Team dimension: Work flexibility $\left(p_{4}\right)$ reflects the ability of the provider to deal with the abnormal situation flexibly in the process of the project to make the project go smoothly; past performance $\left(p_{5}\right)$ refers to the past performance of the supplier; higher education ratio $\left(p_{6}\right)$ indicates the proportion of highly educated members of the provider.

3. Moral dimension: Reliability $\left(p_{7}\right)$ means the stability of the provider to the determined supply and demand service; security $\left(p_{8}\right)$ represents the protection degree of the supplier to the relevant important information of the demander. Assuming that a supplier has completed packaging design service for the corresponding demanders $\mathrm{n}$ times, in which there are a breaches of contract and $\mathrm{b}$ times of leakage of providers' important information, then $p_{7}=\frac{n-a}{n}, p_{8}=\frac{n-b}{n}$.

Among the indicators above, $p_{4}, p_{5}$ and $p_{6}$ are linguistic variables and the linguistic evaluation set is as follows.

Table1. Linguistic evaluation set

\begin{tabular}{cc}
\hline Evaluating language variables & Triangular fuzzy number $\left(a^{l}, a^{m}, a^{n}\right)$ \\
\hline Extremely good & $(0.9,1,1)$ \\
Very good & $(0.7,0.9,1)$ \\
Good & $(0.5,0.7,0.9)$ \\
Common & $(0.3,0.5,0.7)$ \\
Bad & $(0.1,0.3,0.5)$ \\
Very bad & $(0,0.1,0.3)$ \\
Extremely bad & $(0,0,0.1)$ \\
\hline
\end{tabular}

Supposing that the set of experts is $D=$ $\left\{D_{1}, D_{2}, \ldots, D_{c}\right\}$ and the weight set of experts is $H=$ $\left\{h_{1}, h_{2}, \ldots, h_{c}\right\}$ and $\sum_{e=1}^{c} h_{e}=1$, then $p_{4}=\sum_{e=1}^{c} h_{e}^{4} \times$ $\left(\frac{a_{4}^{l}+2 a_{4}^{n}+a_{4}^{m}}{4}\right), \quad p_{5}=\sum_{e=1}^{c} h_{e}^{5} \times\left(\frac{a_{5}^{l}+2 a_{5}^{n}+a_{5}^{m}}{4}\right), \quad p_{6}=$ $\sum_{e=1}^{c} h_{e}^{6} \times\left(\frac{a_{6}^{l}+2 a_{6}^{n}+a_{6}^{m}}{4}\right)$. In these formulas, $h_{e}^{i}$ shows the weight of expert e when evaluating index $i$.

Due to the different attribute trends of the evaluation indicators, they can be generally divided into positive and negative types. From the perspective of the demander, the classification of each indicator is as follows. 
Table2. Classification of evaluation index

\begin{tabular}{cl}
\hline Index name & Index type \\
\hline Design price $p_{1}$ & Negative \\
Design time $p_{2}$ & Negative \\
Design quality $p_{3}$ & Positive \\
Working flexibility $p_{4}$ & Positive \\
Past performance $p_{5}$ & Positive \\
Higher education ratio $p_{6}$ & Positive \\
Reliability $p_{7}$ & Positive \\
Security $p_{8}$ & Positive \\
\hline
\end{tabular}

\subsection{Expression of Problem}

Assuming that the evaluation model of the human resource provider in packaging design project is $r=$ $\left\{p_{1}, p_{2}, \ldots, p_{8}\right\}$, the set of the supplier is $R=\left\{r_{1}, r_{2}, \ldots, r_{n}\right\}$, then the provider's property set is

$$
R=\left[\begin{array}{c}
r_{1} \\
r_{2} \\
\vdots \\
r_{n}
\end{array}\right]=\left[\begin{array}{lllc}
p_{11} & p_{12} & & p_{18} \\
p_{21} & p_{22} & \cdots & p_{28} \\
& \vdots & \ddots & \vdots \\
p_{n 1} & p_{n 2} & \cdots & p_{n 8}
\end{array}\right]
$$

The problem to be solved in this paper is how the demander makes a decision of choosing according to the attribute set of the supplier.

\section{OPTIMIZATION MODEL AND METHOD}

\subsection{The Objective Weight of Evaluation Index Is Determined by Entropy Weight Method}

Entropy weight method [10] is an effective method to determine the objective weight of indicator. Generally, supposing that the number of evaluation objects and evaluation indexes are $\mathrm{m}$ and $\mathrm{n}$ respectively, according to the specific index information of each evaluation object, we can get the following initial matrix.

$$
R=\left[\begin{array}{cccc}
x_{11} & x_{12} & & x_{1 n} \\
x_{21} & x_{22} & \cdots & x_{2 n} \\
& \vdots & \ddots & \vdots \\
x_{m 1} & x_{m 2} & \cdots & x_{m n}
\end{array}\right]
$$

Then the following steps are adopted to calculate the objective weight.

1. Since the evaluation indexes are divided into positive and negative types, it is necessary to standardize them, we can use the following two formulas.

$$
\begin{aligned}
b_{i j} & =\frac{x_{i j}-\min x_{j}}{\operatorname{maxx}_{j}-\min x_{j}} \\
b_{i j} & =\frac{\operatorname{maxx}_{j}-x_{i j}}{\max _{j}-\min x_{j}}
\end{aligned}
$$

In them, $\max _{j}$ and $\min x_{j}$ express the maximum and minimum values of the indexes in column $\mathrm{j}$ of the indicator attribute set. The positive and negative indicators were standardized by formula (1) and formula (2) respectively, then $B=\left(b_{i j}\right)_{m \times n}$ is got.

2 . The information entropy of index can be figured out by using the following formula.

$$
e_{j}=-(\ln m)^{-1} \sum_{i=1}^{m} p_{i j} \ln p_{i j}
$$

In the formula above, we know $p_{i j}=\frac{b_{i j}}{\sum_{i=1}^{m} b_{i j}}$, and when $p_{i j}=0$, it can be realized that $p_{i j} \ln p_{i j}=0$.

3 . Working out the entropy weight of each index, as known as the objective weight.

$$
l_{j}=\frac{1-e_{j}}{\sum_{j=1}^{n}\left(1-e_{j}\right)}
$$

\subsection{The Subjective Weight of Evaluation Index Is Determined by Five Scale Valuation Method}

In this paper, the five scale valuation method [11] is used to determine the subjective weight of evaluation index, the details are as follows.

1. Supposing that the number of the evaluation indicators is $n, d_{j k}$ represents the five scale value of index $\mathrm{j}$ to index $\mathrm{k}$. Evaluating the indicator set according to Table 3 , the matrix D can be obtained, which are shown below.

Table3. Five scale value

\begin{tabular}{cc}
\hline Comparison & Value \\
\hline Evaluation index $j$ is as important as $k$ & $d_{j k}=d_{k j}=4$ \\
Evaluation index $j$ is slightly more important than $k$ & $d_{j k}=4+1, d_{k j}=4-1$ \\
Evaluation index $j$ is more important than $\mathrm{K}$ & $d_{j k}=4+2, d_{k j}=4-2$ \\
Evaluation index $j$ is increasingly more important than $\mathrm{k}$ & $d_{j k}=4+3, d_{k j}=4-3$ \\
Evaluation index $j$ is specially more important than $\mathrm{k}$ & $d_{j k}=4+4, d_{k j}=4-4$ \\
\hline
\end{tabular}

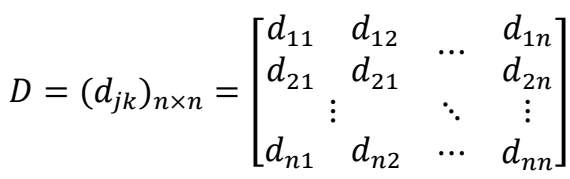

2. Use the following formula to calculate the sum of the five scale values of the evaluation indexes.

$$
s_{j}=\sum_{k=1}^{n} d_{j k}
$$

3. The subjective weight of the evaluation indexes can be figured out by the following formula.

$$
g_{j}=\frac{s_{j}}{\sum_{j=1}^{n} s_{j}}
$$

\subsection{Determination of Comprehensive Weight of Evaluation Index}

If the objective weight of each evaluation index is denoted 
by $L=l_{j}=\left(l_{1}, l_{2}, \ldots, l_{n}\right)$ and the subjective weight is denoted by $G=g_{j}=\left(g_{1}, g_{2}, \ldots, g_{n}\right)$, then we can use the formula

$$
W=w_{j}=\frac{l_{j} \times g_{j}}{\sum_{j=1}^{n} l_{j} \times g_{j}}
$$

to obtain the comprehensive weight of the indexes.

\subsection{Evaluation and Optimization Based on Ideal Point Method}

The ideal point method [12] is a method for further selection by calculating the closeness between the evaluation object and the ideal target value, the specific steps are as follows.

1. Assuming that the number of evaluation objects is $m$ and the number of evaluation indexes is $n$, then the initial matrix can be constructed as follow.

$$
R=\left[\begin{array}{c}
r_{1} \\
r_{2} \\
\vdots \\
r_{m}
\end{array}\right]=\left[\begin{array}{cccc}
p_{11} & p_{12} & \ldots & p_{1 n} \\
p_{21} & p_{22} & \cdots & p_{2 n} \\
& \vdots & \ddots & \vdots \\
p_{m 1} & p_{m 2} & \cdots & p_{m n}
\end{array}\right]
$$

2. Because the indexes have two different types, it is necessary to carry out the same trend processing. In this paper, the reciprocal method is used, according to the formula

$$
p_{i j}^{\prime}=\frac{1}{p_{i j}}
$$

we can get

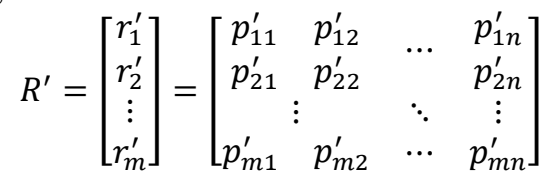

Owing to most of the evaluation indexes in this paper are positive ones, the negative ones will be taken as the reciprocal to make them have the same trend as the positive ones when synchronizing.

3. Using to the formula

$$
p_{i j}^{*}=\frac{p_{i j}^{\prime}}{\sqrt{\sum_{i=1}^{m}\left(p_{i j}^{\prime}\right)^{2}}}
$$

to standardize the data and obtain

$$
R^{*}=\left[\begin{array}{c}
r_{1}^{*} \\
r_{2}^{*} \\
\vdots \\
r_{m}^{*}
\end{array}\right]=\left[\begin{array}{cccc}
p_{11}^{*} & p_{12}^{*} & \ldots & p_{1 n}^{*} \\
p_{21}^{*} & p_{22}^{*} & & p_{2 n}^{*} \\
& \vdots & \ddots & \vdots \\
p_{m 1}^{*} & p_{m 2}^{*} & \cdots & p_{m n}^{*}
\end{array}\right]
$$

4. Combining with the comprehensive weight of each evaluation index, the weighted normalization matrix is got as follow.

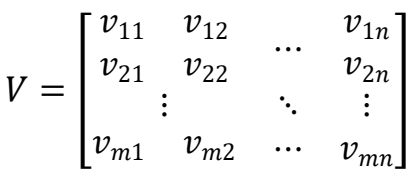

$$
\begin{aligned}
& =\left[\begin{array}{cccc}
w_{1} p_{11}^{*} & w_{2} p_{12}^{*} & \ldots & w_{n} p_{1 n}^{*} \\
w_{1} p_{21}^{*} & w_{2} p_{22}^{*} & & w_{n} p_{1 n}^{*} \\
& \vdots & \ddots & \vdots \\
w_{1} p_{m 1}^{*} & w_{2} p_{m 2}^{*} & \cdots & w_{n} p_{m n}^{*}
\end{array}\right]
\end{aligned}
$$

5. Determining the positive and negative ideal points.

Positive ideal point $V^{+}=\left\{\left(\max v_{i j}, j \in\right.\right.$

$\left.\left.J^{+}\right),\left(\min _{i j}, j \in J^{-}\right)\right\}=\left(v_{1}^{+}, v_{2}^{+}, \ldots, v_{n}^{+}\right)$

Negative ideal point $V^{-}=\left\{\left(\operatorname{minv}_{i j}, j \in\right.\right.$

$\left.\left.J^{+}\right),\left(\max v_{i j}, j \in J^{-}\right)\right\}=\left(v_{1}^{-}, v_{2}^{-}, \ldots, v_{n}^{-}\right)$

In the two formulas above, $J^{+}$and $J^{-}$respectively represent the positive and negative evaluation index column.

6. Calculating the distance.

$$
\begin{aligned}
& S_{i}^{+}=\sqrt{\sum_{j=1}^{n}\left(v_{i j}-v_{j}^{+}\right)^{2}} \\
& S_{i}^{-}=\sqrt{\sum_{j=1}^{n}\left(v_{i j}-v_{j}^{-}\right)^{2}}
\end{aligned}
$$

7. Calculating the closeness and make a choice.

$$
Z_{i}^{*}=\frac{s_{i}^{-}}{S_{i}^{+}+S_{i}^{-}}
$$

At this time, the closest is the best.

\section{APPLICATION EXAMPLE}

A packaging company $\mathrm{H}$ has a design project and needs to complete by selecting appropriate human resource because of the business development. Now there are five candidate providers that are $r_{1}, r_{2}, r_{3}, r_{4}$ and $r_{5}$, the supply information is as follows.

Table4. Supply information

\begin{tabular}{ccccccccc}
\hline Supplier & $\begin{array}{c}\text { Design } \\
\text { price }\end{array}$ & $\begin{array}{c}\text { Design } \\
\text { time }\end{array}$ & $\begin{array}{c}\text { Design } \\
\text { quality }\end{array}$ & $\begin{array}{c}\text { Working } \\
\text { flexibility }\end{array}$ & $\begin{array}{c}\text { Past } \\
\text { performance }\end{array}$ & $\begin{array}{c}\text { Higher } \\
\text { education } \\
\text { ratio }\end{array}$ & Reliability & Security \\
\hline$r_{1}$ & 57 & 9 & 0.85 & 0.66 & 0.83 & 0.77 & 0.57 & 0.75 \\
$r_{2}$ & 47 & 6 & 0.63 & 0.60 & 0.72 & 0.87 & 0.73 & 0.82 \\
$r_{3}$ & 59 & 12 & 0.93 & 0.80 & 0.78 & 0.84 & 0.77 & 0.90 \\
$r_{4}$ & 52 & 10 & 0.67 & 0.92 & 0.66 & 0.75 & 0.94 & 0.72 \\
$r_{5}$ & 55 & 7 & 0.73 & 0.96 & 0.91 & 0.71 & 0.67 & 0.93 \\
\hline
\end{tabular}

At this point, making the following analysis and decision-making so as to let company $\mathrm{H}$ choose the best provider.

\subsection{Determination of Objective Weight of Evaluation Index}

According to the supply information, the objective weight 
vector of each evaluation index is obtained from the formula (1) to (4), that is $L=$ $(0.14,0.10,0.15,0.13,0.12,0.12,0.11,0.13)^{T}$.

\subsection{Determination of Subjective Weight of Evaluation Index}

For the three dimensions of evaluation index system, the five scale valuation method is carried out by the human resource demand side, the matrix $D=\left(d_{j k}\right)_{3 \times 3}=$ $\left[\begin{array}{lll}4 & 5 & 4 \\ 3 & 4 & 6 \\ 4 & 2 & 4\end{array}\right]$ is got. According to formula (5) and (6), the weight of each dimension is $G=(0.36,0.36,0.28)$. Similarly, we can obtain the weight of each index under different dimensions, that are design dimension $G_{1}=$ $(0.36,0.39,0.25)$, team dimension $G_{2}=$ $(0.39,0.28,0.33)$ and moral dimension $G_{3}=(0.50,0.50)$. Therefore, the subjective weight vector of each evaluation index is $G=$ $(0.13,0.14,0.09,0.14,0.10,0.12,0.14,0.14)^{T}$.

\subsection{Determination of Comprehensive Weight of Evaluation Index}

The comprehensive weight vector of each evaluation index is determined according to formula (7), that is $W=$ $(0.15,0.11,0.11,0.15,0.09,0.12,0.12,0.15)^{T}$

\subsection{Evaluation and Optimization}

According to the supply information and combining with the comprehensive weight of the indexes, the closeness between each supplier and the ideal point is obtained as follows by formula (8) to (14).

Table5. Closeness between supplier and ideal point

\begin{tabular}{cccccc}
\hline Supplier & $r_{1}$ & $r_{2}$ & $r_{3}$ & $r_{4}$ & $r_{5}$ \\
\hline$Z_{i}^{*}$ & 0.43 & 0.25 & 0.72 & 0.61 & 0.54 \\
\hline
\end{tabular}

Obviously, the provider $r_{3}$ is the closest one to the ideal point, so $\mathrm{H}$ should choose $r_{3}$.

\section{CONCLUSION}

Packaging design plays a vital role in the development of packaging enterprises, and even can be related to the survival of them. In the packaging design project, human resource is a key factor. Therefore, how to choose the human resource in packaging design project is a crucial problem for packaging enterprises. Based on the context, this paper first establishes the human resource evaluation index system, then the objective weight and the subjective weight of the indexes are worked out by using the entropy weight method and the five scale valuation method respectively. Finally, the ideal point method is applied to evaluate the suppliers, which can provide the basis for the selection of the demander. This method can solve the problem of selection of human resource supplier for the demander in packaging design project, and it has clear thinking and strong practicability as well.

\section{ACKNOWLEDGMENTS}

Fund project of Guangxi Aviation Logistics Research Center (2018KFJJHKWL01)

Research on the innovation mode of system and mechanism of higher vocational colleges based on social service (GXGZJG2018B150)

\section{REFERENCES}

1. TANG Y F, TANG L C. (2020) Importance of Packaging Design to Beverage Sales. Packaging Engineering, 41(16):305-310.

2. QIAN T Y, LI H Z. (2010) Importance of the Female Health Food Position Strategy in Packaging Design. Packaging Engineering, 31(16):117-119.

3. ZHANG H B. (2020) Application of Calligraphy Elements in Modern Packaging Design. Packaging Engineering, 41(16):301-304.

4. CHEN X. (2020) Analysis on Interesting Design Strategies for Packaging of Edible Fungi Products for Children. Edible Fungi of China, 39(12):189-192.

5. JI C. (2020) The Industrialization Development Status and Application of Calligraphy Art in Packaging Design. Packaging Engineering, 41(04):298-301.

6. LING L, CHEN Y L, ZHANG Y Y, LIU J. (2019) Assessment and selection for human resource supply in cloud manufacturing environment. Computer integrated manufacturing system, 25(08):2059-2068.

7. LI Y W. (2020) Human Resource Management Strategy of Edible Fungi Industry. Edible Fungi of China, 39(05):84-86.

8. ZHANG L X, FU J Y, JIANG H T, CHE L N. (2016) Competitiveness Evaluation on the Sci-tech Human Resources in China's Regional Central City. Journal of Northeastern University(Natural Science), 37(02):290-294.

9. LU C H, KOU J S. (2019) Multi-attribute Decision Making and Adaptive Genetic Algorithm for Solving QoS Optimization of Web Service Composition. Computer Science, 46(02):187-195.

10. WANG P, YAN L L, GUO W C. (2020) Evaluation of grassroots earthquake science popularization capability based on AHP-entropy method. Journal of Safety Science and Technology, 16(12):170-175.

11. WANG B, LI Y J. (2013) Five scale valuation and fuzzy comprehensive evaluation on human-machine interface quality. Computer Applications and Software, 30(02):22-25.

12. JIANG R, GUO J B. (2017) Safety Evaluation of Hydraulic Steel Gate Based on Ideal Point Method. Water Resources and Power, 35(11):183-185+211. 